Artículo de Reflexión E13A12. * Recibido 15.08.2018. * Aceptado versión final: 06.11.2018. JEL: M14 * Pp.29-42 * doi:10.33571/teuken.v10n14a1

\title{
Más allá de los Paraísos Fiscales. La ética contable como factor determinante en la construcción de confianza.
}

\author{
Beyond Fiscal Paradises. \\ Accounting ethics as a determinant factor \\ in the construction of trust. \\ Tatiana Ospina Marulanda \\ Estudiante
}

COLOMBIA

\begin{abstract}
Resumen: El artículo analiza cómo las políticas estatales, influidas por intereses privados, refuerzan y expanden la desigualdad social y dan lugar a una ética contable que no cuestiona las acciones y se orienta a satisfacer intereses corporativos. Se evidencia cómo los estados son absorbidos por organizaciones que persiguen beneficios a corto plazo y por el control totalitario de la economía. Se examina el tema de las filtraciones relacionadas con organizaciones offshore y paraísos fiscales, develando el deterioro ético del profesional contable. Finalmente, se concluye que el contador público debe ser garante de confianza pública y que sus acciones tienen repercusiones sociales.
\end{abstract}

Palabras clave: ética contable; profesional contable; paraísos fiscales; estado; organización.

Abstract: The article analyzes how state policies, influenced by private interests, reinforce and expand social inequality and give rise to an accounting ethic that does not question actions and is aimed at satisfying corporate interests. It shows how states are absorbed by organizations that pursue short-term benefits and totalitarian control of the economy. The topic of leaks related to offshore organizations and tax havens is examined, revealing the ethical deterioration of the accounting professional. Finally, it is concluded that the public accountant must be guarantor of public trust and that his actions have social repercussions.

Keywords: accounting ethics; accounting professional; paradise papers; state; organization

Tecnológica

de Antioquia

Tatiana Ospina es estudiante de Contaduría Pública del Tecnológico de Antioquia, Tecnóloga en Contabilidad y Finanzas del SENA. Participante como ponente en el IV Encuentro Nacional de Semilleros y Grupos de Investigación en la Universidad Pedagógica y Tecnológica de Colombia, sede Chiquinquirá y en el III Congreso Latinoamericano de Investigadores Contables.

Contacto: tati9611@gmail.com

Teuken Bidikay Vol. 10 № 14 (Medellín, Colombia) * Ene-Jun 2019. ISSN: 2215-8405 - e-ISSN 2619-1822. Pp. 29-42 


\section{Além dos Paraísos Fiscais.}

Uma ética contábil como um fator determinante na construção da confiança

Resumo: $O$ artigo analisa como as políticas estaduais, influenciadas por interesses privados, reforçam e ampliam a desigualdade social e dão origem a uma ética contábil que não questiona ações e visa à satisfação de interesses corporativos. Mostra como os estados são absorvidos pelas organizações que buscam benefícios de curto prazo e controle totalitário da economia. O tópico de vazamentos relacionados a organizações offshore e paraísos fiscais é examinado, revelando a deterioração ética do profissional contábil. Por fim, conclui-se que o contador público deve ser garante da confiança do público e que suas ações têm repercussões sociais.

Palavras-chave: ética contábil; profissional contábil; paraísos fiscais; estado; organização

\section{Introducción}

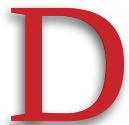

adas las dinámicas del mundo actual, la ética profesional contable está en riesgo continuo, debido al poder que las organizaciones tienen sobre el estado y ejercen sobre los sujetos. Colombia no ha sido ajena a dicha problemática, por tal razón, se hace necesario exponer el tema del estado y la organización como causantes del deterioro de la ética contable, pues permite analizar la de decadencia de la profesión contable, y proponer cambios que conduzcan a un ejercicio de lo contable con miramientos éticos y sociales. Este artículo se desarrolla a partir de la revisión y análisis documental sobre la ética del profesional contable y su problematizarla en un contexto de globalización y de las relaciones de poder que giran en torno a las organizaciones y el estado. En este sentido, Chomsky señala que:

La era neoliberal de la última generación ha añadido su toque propio a esa imagen clásica: los amos salen de las capas superiores de economíascadavezmásmonopolizadas; lasinstitucionesfinancieras son colosales y, a menudo, depredadoras; y las multinacionales están protegidas por el poder del Estado y por las figuras políticas que, en gran medida, representan sus intereses (2016: 12).

La ética del contador no suele estar muy conectada con el mundo académico, pues esta gira más en torno a lo procedimental y hace que recaiga en la responsabilidad asumida en la Ley 43 de 1990, que regula los principios básicos de la ética profesional contable, para el fundamento del desarrollo y cumplimiento de sus funciones. ${ }^{1}$

1 Estos se detallan en el Capítulo IV, Título I, Artículo 37, definiéndolos como: integridad, independencia, objetividad, responsabilidad, confidencialidad, competencia y actualización profesional, observancia de las disposiciones normativas, difusión y colaboración, respeto entre colegas, conducta ética. 
Es de notar que se ha dado un daño real a la ética, pues se considera ético seguir las reglas, escondiendo el verdadero hecho. Esto es evidenciado en una serie de filtraciones relacionadas con organizaciones offshore y paraísos fiscales, ${ }^{2}$ investigadas por The International Consortium of Investigative Journalists (ICIJ). ${ }^{3}$

De igual modo, es necesario entender que el deterioro de la ética de la profesión contable se da en los ámbitos económico y social, y las sociedades de control han ayudado a este proceso de degradación, porque como dice Chomsky:

La concentración aguda de riqueza en manos privadas ha venido acompañada de una pérdida del poder de la población general. La gente se percibe menos representada y lleva una vida precaria con trabajos cada vez peores. El resultado es una mezcla de enfado, miedo y escapismo. Ya no se confía ni en los mismos hechos. Hay quien le llama populismo, pero en realidad es descrédito de las instituciones (2016: párr. 9).

La ausencia de valores éticos repercute en grandes escándalos de corrupción, desfigurando la verdadera ética del contador; debido a que "el apoyo empresarial se traduce directamente en poder político" (Chomsky, 2016: 97).

\section{Ética contable}

Es necesario reconocer la responsabilidad social que tiene el contador público, pues sus actuaciones están presentes en cada proceso que enfrentan las organizaciones y el estado en escándalos de corrupción, evasión fiscal y otros hechos. El contador público afronta cuestionamientos sobre su lealtad a la verdad (González, 1982). Sobre la ética se han asumido diferentes prácticas, una de ellas es cumplir las reglas; la segunda, es una ética complaciente con el patrón, y la tercera, es la ética como necesidad del deber ser y no ser.

Por su parte, Ariza (2009) presenta tres características fundamentales de la ética: 1) tiene un sentido individual y es una decisión libre y consciente, donde la responsabilidad es intransferible; 2) cuenta con un sentido social, que actúa como acción del ser social y dando importancia a lo

2 Offshore Leaks (2013), Luxembourg Leaks (2014), Swiss Leaks (2015), Panama Papers (2016) y Paradise Papers (2017).

3 Aplicación pública que busca eliminar el secreto de los paraísos fiscales y hacer investigación con respecto a éstos. 
relacional, ${ }^{4}$ y 3) tiene un factor regulatorio que indica cómo debe ser el comportamiento del sujeto y el cumplimiento de las normas.

La sociedad trabaja en forma mecánica, constituyendo una lógica incompleta (Giraldo, 2010). La educación se centra en cumplir las necesidades empresariales, marginando al sujeto de una educación integral y crítica. No es de extrañar que, desde los últimos escándalos, se involucra al contador público, de ahí que sea necesario cuestionar las instituciones y contextos que inciden en la formación del sujeto contable.

Las sociedades de control son una de las principales causas que hace que el contador público olvide su verdadera ética, pues debe responder a lo que persigue una organización. Otra causa es el "El problemático ambiente de los negocios y el oscuro entramado de ciertas prácticas antiéticas por parte de grandes corporaciones han situado al Contador Público y la ética profesional dentro de juicios que ponen en duda su compromiso con la sociedad" (Pinilla y Álvarez, 2013: 132).

De igual manera, Vargas y Católico afirman que:

El contador público está en la obligación, tanto social como profesional, de ser un abanderado de la verdad, promulgar siempre la ética y el respeto a la profesión, promover dentro de los contadores profesionales el respeto, la transparencia y la honestidad en cada acto de su ejercicio, siendo ejemplo claro para los futuros profesionales contables (2007: 131).

La información contable debe defender su orientación hacia lo público, pues ha sido capturada por intereses privados, de los que se han derivado fraudes empresariales. Así lo mencionan Gonzalo y Garvey: "(...) el conjunto de personas relacionadas con la información contable tiene un reto de difícil superación, como es, la acusación de ser un aliado necesario de buena parte de los escándalos" (2007: 14).

La inclinación a dar indicadores financieros sin tener en cuenta la ética que debemos ejercer, el recurso humano que debemos cuidar y la sociedad que debemos construir, es consecuencia de que se ha circunscrito la ética a una norma, y el criterio y juicio contable responde a cumplir con las exigencias de rentabilidad de las organizaciones. Los empresarios están más interesados en las ventajas que ofrece la elución o evasión de impuestos, sobre quien puede darle soluciones para que su recurso 
humano alcance un mejor desempeño por encima de su bienestar y dignidad humana.

Un caso que ilustra lo anterior son las filtraciones relacionadas con organizaciones offshore y paraísos fiscales, las cuales dejan el papel del profesional contable en muy bajo nivel, pues es el actor encargado de destinar los recursos de la empresa, no solo financieros, también de recurso humano, haciendo que la organización pueda estar en funcionamiento.

Una figura presente en estos escándalos es la del hacktivista/cyberactivista, o también conocidos como hackers (piratas informáticos). Aunque para unos son malos, otros consideran que ayudan a liberarnos de esa muralla que cada día nos crean; es algo como dejar de lado al Gran Hermano expresado en el libro $1984,{ }^{5}$ y lo que un niño dijo:

(...) para mí, no existe ni el bien, ni el mal como tal, es algo que ambas partes comparten en cada uno, es decir, para muchos el diablo es malo porque castiga a los que hicieron el mal, pero en lo que se concibe como ética está bien, porque corrige al que no supo obrar.

Por su parte, Chomsky (2016) señala que el sistema nos neutraliza; la tecnología es una influencia opresora ${ }^{6}$ y la manipulación gubernamental procura otorgar beneficios a quienes ostentan el poder. Debemos notar que los cambios actuales influyen mucho en nuestra profesión, pues revelan las formas en que se usan normas extraterritoriales para jugar con la ética del contador.

\section{El estado y la organización: causantes del deterioro de la ética contable}

Las condiciones económicas, políticas y organizacionales hacen que el papel de la ética contable continúe en decadencia acelerada. Como lo señala López (2011: 187):

(...) se ha manifestado en un afán desmedido, en alguna parte de la población, por acumular riqueza y poder por encima de quien sea y de lo que sea, guiada por un camino facilista y utilizando maniobras para lograr un posicionamiento económico, social y profesional.

5 "Hasta que no tengan conciencia de su fuerza, no se revelarán, y hasta después de haberse revelado, no serán conscientes. Ese es el problema".

6 Todo esto se da por la pereza de leer, la desidia de aprender e investigar, en sí, nos dejamos absorber por un poder que no es democrático. 
De acuerdo con Pinilla y Álvarez (2013), ha sido tanta la miseria social, que hasta las mismas naciones han vendido su conciencia y han sido coaptadas por los deseos e intereses de los que tienen el poder, desviando el papel del estado como garante de los derechos fundamentales y defensor de lo público hacia una función de mediador que garantice los intereses de los grandes poderes económicos a través de la desregulación y la implementación de políticas neoliberales.

El estado está en manos de las corporaciones. Se ha rechazo la "(...) filosofía del Nuevo Nacionalismo que adopta políticas concebidas para proporcionar una distribución más amplia de la riqueza y elevar el nivel de vida de las masas" (Chomsky, 2016: 193). En este sentido, se da un juego político y económico, que ataca a quienes defienden el derecho a la verdad y evidencian que los estados y organizaciones crean estrategias que permiten moldear la economía sin importar las consecuencias, es decir, son capaces de incriminar o asesinar a gente que lucha por lo que en realidad merece y desea cuidar. Como lo expresa Chomsky (citado en Chomsky, 2016: 25):

El derecho a combatir al enemigo interno, como se estableció en la doctrina brasileña, la doctrina argentina, la doctrina uruguaya y la doctrina colombiana, es el derecho a combatir y exterminar a trabajadores sociales, sindicalistas, hombres y mujeres que no apoyan al poder establecido y que se supone que son comunistas extremistas. Yesto podría significar cualquiera, incluidos activistas de los derechos humanos como yo mismo.

A lo largo del tiempo se han "(...) evidenciado casos de comportamientos antiéticos que han llevado a un deterioro del prestigio y la credibilidad del contador público ante la sociedad" (Ramírez y Reyes, 2013: 185), causa por la cual se establecen medidas de vigilancia y control para subsanar o evitar hechos que desacrediten la fe pública del contador.

\section{Serie de filtraciones}

Las filtraciones relacionadas con organizaciones offshore y paraísos fiscales, particularmente, Panama Papers (2016) y Paradise Papers (2017), surgen como detonación de un hackeo, que logra acceder a información secreta, oculta o manipulada. Su fuente anónima (hacker) hace que todo llegue a un tercero, para su efectiva divulgación, en estos casos Wikileaks ${ }^{7}$ (el más conocido o mencionado hasta el momento), la ICIJ, redes sociales,

7 Organización fundada en 2006, con el fin de informar a través de su plataforma sobre documentos filtrados que contienen material sensible de interés público, preservando anonimato de sus fuentes. 
periódicos, redes P2P, etc. Los documentos son extraídos y posteriormente entregados a organizaciones o medios de comunicación que inician la filtración. Las filtraciones (leaks) normalmente son masivas y con datos en crudo (raw), esto significa que quedan disponibles para que cualquiera los consulte, analice, copie, comparta y distribuya. También significa que no tienen ningún procesamiento o estudio; en sí mismos los documentos no dicen mucho, se requiere del análisis extenso y especializado (Delfino, 2017) para dar real significado a lo que los documentos evidencian.

Los paraísos fiscales son atractivos para las organizaciones debido al libre manejo de divisas, la favorabilidad en cuanto a estructuras impositivas, reserva bancaria, siendo determinantes la estabilidad político-económica, y, la ausencia de las obligaciones legales sobre la detección y reporte de operaciones sospechosas.

Una de las grandes preocupaciones es cómo todo se oculta y se hace de manera estratégica para la clase gobernante, ya que son formas de dominar la industria, la organización y las personas. Esto puede ejemplificarse con una situación que menciona Chomsky (2016: 93) "(...) hay una planificación geoestratégica basada en principios racionales y que perduran durante mucho tiempo porque están arraigados en instituciones estables y en sus intereses". Asimismo, esto puede representarse en el "tercer mundo" donde la política solo actúa de la mano de las multinacionales. El estado capitalista desgarra la estructura misma del estado; confluyen relaciones ocultas, se crean legislaciones sin importar las consecuencias, todo por el hecho de que durante el ascenso al poder se recibió financiación por parte de alguna organización.

De lo anterior, cabe preguntarse ¿cómo el contador hace que esos recursos se pasen por alto? ¿dónde queda su responsabilidad social? Claramente, esto se respondió antes: todo recae en la forma como la globalización nos sumerge en las sociedades de poder.

Estos casos suscitaron mucha revuelta en el mundo y mostraron que se trata de convencer a todos que hay una democracia, siendo únicamente operativa para algunos sectores. Según Nino-Moris (2016) las élites controlan los mecanismos, permiten manejar los recursos para ellos mismos porque siempre habrá unos actores ocultos (inversionistas), quienes controlan lo político, económico. Es por eso que Chomsky (2016: 66) afirma:

El apoyo de la democracia es territorio de ideólogos y propagandistas. En el mundo real, el desprecio de la élite por la democracia es la norma. Son abrumadoras las pruebas de que solo se apoya la democracia en la medida en que contribuye a objetivos sociales y económicos. 
Por su parte, Marc Fortuño señala que:

Es importante recordar que el sector financiero depende en sus decisiones de la veracidad que ofrecen los Estados Financieros de cualquier empresa, por lo que no sólo es preciso un correcto marco normativo cuya finalidad sea reflejar la imagen fiel de sus cuentas, sino que la empresa y el departamento contable en particular deben tener la voluntad de aplicar tal normativa, sea cual sea el escenario económico de la empresa. En un escenario de pérdidas, existe un incentivo a maquillar el resultado negativo con cocina contable, por mucho Código de Ética en la práctica contable que exista. Estas prácticas son un fraude que termina generando malas decisiones de inversión y sostienen artificialmente las cotizaciones, hasta que cruda realidad de las cuentas o bien un informe externo de una agencia independiente, desmantela la cocina contable y luego la cotización se hunde (2015: 5).

Lo anterior nos conduce a la Contabilidad Creativa, ${ }^{8}$ concepto llamativo que hace referencia a la flexibilidad de ciertas normas contables, es decir, zonas o áreas grises, posibilitando la manipulación y tergiversación de la información, pudiéndose visualizar en los Panama Papers y Paradise Papers.

Estos escándalos conllevan a que se juzgue a gobernantes y contadores, quienes son lasfiguras que participan y avalan la utilización o tergiversación de la información contable. Es una conducta apartada de la ética profesional, que desemboca en la búsqueda de beneficios particulares, sacando ventaja de la transgresión de valores y normas. En este sentido, Gonzalo y Anne Garvey (citados en Ariza, 2009: 33) "(...) piensan que, desde su perspectiva, identifican que la contabilidad se encuentra sumergida en una profunda crisis de credibilidad y de identidad societal".

\section{Panama Papers y Paradise Papers}

Los Panama Papers son documentos confidenciales, que hacen referencia a la naturaleza de la información revelada en las presuntas operaciones de evasión de impuestos en paraísos fiscales y las consecuencias de las revelaciones del bufete de abogados panameño Mossack Fonseca. The Guilty Code (2016) señala que la filtración de registros financieros offshore expone una red global de crimen y corrupción, involucrando a 140 políticos de alto perfil en 50 países, 100 medios en 78 países y 11.5 millones de documentos en paraísos fiscales. Según la BBC (2016), en Colombia 
las filtraciones involucran a más de 850 personas y organizaciones, entre las cuales se encuentran ex servidores públicos, políticos de todas las tendencias y, principalmente, empresarios.

La revista Dinero (2016) reportó que la DIAN encontró el primer caso que exponía ocultamiento de activos y evasión de impuestos de una firma de abogados, la cual creó más de 40 offshore. De igual manera, el periódico el Tiempo (2017) corroboró que la institución habría dividido todo en cuatro casos, mostrando qué organizaciones habían evadido, cuáles operaban con irregularidad, qué contratos habían realizado; al finalizar, solo doce quedaron para ser procesadas por compra y falsificación de facturas.

En octubre de 2017, el diario El Espectador mostró algunos efectos de los Panama Papers en Colombia, que involucraba a personas que habían eludido impuestos, firmaron contratos ficticios y crearon organizaciones ficticias. Entre los casos aparecieron congresistas, abogados, empresas como Servientrega, Efecty y el entonces presidente Juan Manuel Santos.

Estos datos fueron obtenidos por el diario alemán Süddeutsche Zeitung, que los compartió con ICIJ, y fueron divulgados el 3 de abril de 2016 por varios medios. Las revelaciones continúan apareciendo (El Espectador, 2017). En el hermetismo de las tiendas offshore se puede evidenciar cómo se interpone el derecho a que la sociedad esté informada, por eso Chomsky (2016: 186) afirma:

Hay importantes barreras en la lucha por la justicia, la libertad y la dignidad, incluso más allá de la intensa guerra de clases que el mundo empresarial, con una profunda conciencia de clase, libra sin cesar, siempre con el 'apoyo indispensable' de los Gobiernos que en gran medida controla.

Dados los escándalos desatados por los Panama Papers, algunos contadores y revisores fiscales fueron llamados a declarar, por faltas a la fe pública, la ética profesional y la responsabilidad social. Estos debieron atestiguar el hecho de que su firma estuviese en los documentos, y decir que no sabían nada acerca de esos movimientos. ¿Dónde queda la ética del profesional? Claramente, en la imposición de las organizaciones para jugar con lo que no debemos ser.

La Nación (2017) reveló que, dieciocho meses después de los Panama Papers, el centro de investigación ICIJ comenzó a revelar los Paradise Papers, gracias a la ayuda del periódico alemán Süddeutsche Zeitung; sin embargo, para algunos países continuar con este proceso fue chocante, porque estaban implicados. 
El nombre de Paradise Papers describe los perfiles idílicos de muchas de las jurisdicciones extraterritoriales, cuyos trabajos se dieron a conocer, incluyendo Bermudas, cuartel general de Appleby, principal compañía involucrada (BBC, 2017, párr.4). Al igual que en los Panama Papers, se revelaron cientos de multinacionales, políticos, empresarios, celebridades públicas, firmas legales, instituciones financieras y claramente, contadores involucrados en estos sectores, donde adoptan otro tipo de legislación para desviar y ocultar fondos o transacciones (La Nación, 2017). En palabras de Chomsky:

Para la mayoría de la población, los sueldos reales se estancaron en gran medida y la gente solo pudo salir adelante mediante un gran aumento de la carga de trabajo (muy superior a la de Europa), endeudamiento insostenible $y$, desde los años Reagan, burbujas repetidas que crearon riqueza ficticia, la cual desapareció, sin remedio, cuando estallaron; tras ese estallido de la burbuja, a menudo sus responsables fueron rescatados por el contribuyente. En paralelo, el sistema político se ha ido destruyendo progresivamente y ha metido cada vez más a los dos partidos hegemónicos en los bolsillos de las grandes empresas, con una escalada de costes electorales (2016: 101).

Se crea una nueva legislación (¿creada por quién y para qué?) diseñada, planeaday puesta en marcha, sabiéndose previamente los efectos nefastos sobre la sociedad; se da un deterioro del empleo y de la economía como tal, debilitando la capacidad real del individuo para influir en los asuntos políticos y arrojando enormes beneficios para unos pocos. El problema recae en que deben cumplirse unos compromisos determinados por ambiciones que dependen extensamente de la ocultación de relaciones y capitales.

Sobre los Panama Papers y los Paradise Papers, Dans plantea:

Son todo un signo de los tiempos: cambian los negocios, porque lo que no sea razonablemente transparente será cada vez más obligado a serlo, cambia la investigación periodística, y terminará cambiando hasta los marcos legislativos que la regulan. Pero, sobre todo, es un esfuerzo brutal y un proyecto de sistemas y tecnologías de información que debería estudiarse en las universidades para seguir descubriendo la verdad (2016).

\section{Haciendo historia}

El pasado, presente y futuro dependen de la actuación de los contadores, quienes hacen historia, al ser los encargados del manejo y 
registro transparente de los recursos económicos y financieros de una organización. Dadas las circunstancias evidenciadas en los hechos que relatan los Papers, está en manos de ellos establecer la construcción de una sociedad. Los casos que involucran la ética del contador "han determinado la necesidad de una nueva ética que posibilite la supervivencia del ser humano en el futuro" (Dueñas y Villa, 2010: 71). Nuestra ética necesita florecer a diario, porque el cambio lo hacemos todos y ahora. La decisión de ejercer una gran profesión parte de trabajar por encima de los intereses individuales, apoyando el deseo de servir, tener clara las ideas, afrontar con honestidad y transparencia la profesión contable, la cual vislumbrará un futuro mejor.

El contador "no puede desarraigarse de su obligación ética y deontológica, ya que su actuar está encaminado a la consecución de un entorno más transparente y justo, ayudando con su labor y ejemplo a la ecuanimidad, imparcialidad, rectitud, honestidad de su profesión" (Pinilla y Álvarez, 2013: 144). Consecuentemente, hay que rescatar esos valores inculcados desde el hogar, continuados en la escuela, que son ejes fundantes de lo que somos y seremos, perseguir el derecho a la verdad. En nosotros como contadores recae el deber de afrontar que somos parte de esa verdad, si no la respetamos seremos falsificadores.

Las decisiones y acciones del contador tienen gran impacto. Son los contadores quienes están en un marco de referencia, acatan órdenes, aceptan estructuras existentes y no se cuestionan lo que en realidad pueden hacer. Es por eso que Fortuño (2015) dice que "La historia ha demostrado que a pesar de la profesionalidad del contable y de la ética que éste procese, la presión económica es más intensa, lo que ha propiciado escándalos contables muy sonados" (párr. 4).

Tenemos que hacer frente a los eslóganes idealistas, investigar quién corrompe y quién se deja corromper, como lo plantean Taborda y Jiménez (2013): "en la actualidad, se piensa en la figura del contador público como un sujeto que ha recibido una formación profesional enfocada sólo en el desarrollo de habilidades inherentes a aspectos contables, fiscales y financieros" (p. 69). Empero, se ha dejado a un lado el compromiso social que el contador tiene, lo que, en parte, ha sido provocado por sectores que actúan en la sombra de la academia.

\section{Conclusiones}

La ética del contador público se forma, en gran parte, en la universidad a partir de la formación recibida, de ahí que esta también haga parte de un conjunto de relaciones de poder y control. Como resultado del ejercicio crítico y analítico expuesto en este texto, debemos fortalecer 
el aprendizaje sobre las normas, para crear puntos crítico-constructivos frente a cambios o problemáticas que se presenten en un futuro. De igual modo, se puede cuestionar la crisis que vive la ética contable y la manera cómo la globalización absorbe al profesional contable en un mundo de falsa realidad, debido a que solo se busca hacer el bien relativizado por las empresas sin considerar el costo social.

Es gratificante ver cómo hay hackers y periodistas que buscan, a riesgo propio, sacar a la luz información, para hacerla accesible y comprensible; de igual modo, la manera en que facilitan la divulgación por diversos medios. Gracias a ellos por hacer que los contadores pensemos acerca de nuestros ideales y del cambio que podemos propiciar.

El llamado es para estudiantes, profesionales e investigadores a incorporar el análisis de los fenómenos que han deteriorado la ética contable y los mecanismos relativos al interés público; alcanzando una comprensión interdisciplinaria de la realidad integrada al ámbito social, pues allí nace y se imparte la justicia, la dignidad y la libertad.

\section{Referencias bibliográficas}

1. ARIZA, Efrén Danilo. (2009). Una aproximación a la ética contable en la globalización. En: Revista Contaduría Universidad de Antioquia, № 54. Medellín: Universidad de Antioquia.

2. BBC Mundo. (2016). Cómo afectan las revelaciones de Panamá Papers a América Latina. Disponible en Internet: http://www.bbc.com/mundo/ noticias/2016/04/160404_como_afectan_revelaciones_panama_papers_ america_latina_dgm Consultado 05.02.2018.

3. BBC Panorama. (2017). Paradise Papers: el refugio tributario de Apple al descubierto. Disponible en Internet: http://www.bbc.com/mundo/noticiasinternacional-41894564 Consultado 05.02.2018.

4. CHOMSKY, Noam. (2016). ¿Quién domina el mundo? Barcelona: Ediciones B, S.A.

5. COLOMBIA. Congreso de la República. (1990). Ley 43. Bogotá, 13 de diciembre de 1990.

6. DANS, Enrique. (2016). Analizando los Panama Papers como proyecto Tecnológico. Disponible en Internet: https://www.enriquedans.com/2016/04/analizando-lospanama-papers-como-proyecto-tecnologico.html Consultado 15.03.2018.

7. DELFINO, Emilia. (2017). Secretos de Paradise Papers, la investigación que vuelve a exponer el mundo offshore. Diario Perfil. Disponible en Internet: http:// www.perfil.com/paradisepapers/la-cocina-detras-de-paradise-papers-una- 
investigacion-que-vuelve-a-exponer-los-secretos-del-mundo-offshore.phtml Consultado 10.02.2018.

8. DINERO. (2016). DIAN encuentra primer lavado de activos en los Panamá Papers. Disponible en Internet: http://www.dinero.com/pais/articulo/dian-encuentraprimer-caso-de-lavado-de-activos-en-los-panama-papers/224289 Consultado 15.03.2018.

9. DUEÑAS, Sebastián y VILLA, Lida. (2010). Construyendo confianza al interior de la organización desde la ética. Revista Contaduría Universidad de Antioquia, № 57. Medellín: Universidad de Antioquia.

10. El ESPECTADOR. (2017). Lo que se sabe de los Panama Papers un año después. Disponible en Internet: https:/www.elespectador.com/economia/ lo-que-se-sabe-de-los-panama-papers-un-ano-despues-articulo-687212 Consultado:15.03.18

11. EL ESPECTADOR. (2017). Emiratos Árabes invertirá $\$ 1.000$ millones de dólares para extraer oro en Santurbán. Disponible en Internet: https://www.elespectador. com/noticias/medio-ambiente/emiratos-arabes-invertira-1000-millones-dedolares-para-extraer-oro-en-santurban-articulo-722884 Consultado 19.02.2018.

12. ELTIEMPO. (2017). Así fue la investigación de Panama Papers en el país. Disponible en Internet http://www.eltiempo.com/justicia/investigacion/dian-explica-comoinvestigo-panama-papers-en-colombia-138838 Consultado 10.02.2018.

13. FORTUÑO, Marc. (2015). La importancia de la ética en la contabilidad. Disponible en Internet: https://www.euribor.com.es/bolsa/la-importancia-de-la-etica-en-lacontabilidad/ Consultado 09.03.2018.

14. GIRALDO, Gregorio. (2010). Contexto económico, ética y actitud crítica en la formación del contador público. Revista Contaduría Universidad de Antioquia, Nº 57. Medellín: Universidad de Antioquia.

15. GONZÁLEZ, Anselmo. Principios básicos de ética profesional del contador. (1982). Revista Contaduría Universidad de Antioquia, № 1. Medellín: Universidad de Antioquia.

16. GONZALO, José y GARVEY, Anne. (2007). Ética y enseñanza de la contabilidad (una propuesta de discusión). Revista Contaduría Universidad de Antioquia, $\mathrm{N}^{\circ}$ 50. Medellín: Universidad de Antioquia.

17. ICIJ. (2016). Investigation Paradise Papers: Secrets of the global Elite. Disponible en Internet https://www.icij.org/investigations/paradise-papers/ Consultado 10.02.2018.

18. LA NACIÓN. (2017). 10 Claves para entender los Panama Papers. Disponible en Internet: http://www.lanacion.com.ar/2079799-10-claves-para-entender-losparadise-papers Consultado 15.03.2018. 
19. LA NACIÓN. (2017). 'Paradise papers' echan luz sobre los clientes de los paraísos fiscales. Disponible en Internet: https://www.nacion.com/el-mundo/paradisepapers-echan-luz-sobre-los-clientes-de/HYNWTEEHINFKTBBEBW3355XLQU/ story/ Consultado 15.03.2018.

20. LÓPEZ, Óscar. (2011). La revisoría fiscal y la corrupción en Colombia. Revista Contaduría Universidad de Antioquia, № 58-59. Medellín: Universidad de Antioquia.

21. NINO-MORIS, Christian. (2016). "Panama Papers" y la conducta defraudadora. Disponible en Internet: https://www.americaeconomia.com/analisis-opinion/ panama-papers-y-la-conducta-defraudadora Consultado19.02.2018.

22. ORWELL, George. (2007). 1984. España: Ediciones Destino.

23. PINILLA, Jhon y ÁLVAREZ, Johanna. (2013). Del Contador Público y la ética profesional: un dilema inmerso en un ambiente saturado de conflictos morales. Revista Contaduría Universidad de Antioquia, № 63, Medellín: Universidad de Antioquia.

24. RAMÍREZ, Angie y REYES, Julieth. (2013). La importancia del Código de ética internacional en la profesión contable: Contexto colombiano en el proceso de internacionalización. En: Revista Gestión \& Desarrollo, Vol. 10. № 1. Cali: Universidad de San Buenaventura.

25. TABORDA, Cherley y JIMÉNEZ, Gloria. (2013). La Formación Ética y Profesional del Contador Público en el Área Metropolitana de Medellín. (Tesis de grado). Universidad de San Buenaventura, Medellín: Colombia. Disponible en Internet: https://bibliotecadigital.usb.edu.co/bitstream/10819/2224/1/Formacion_Etica_ Profesional_Taborda_2013.pdf Consultado 19.02.2018.

26. THE GUILTY CODE. (2016). El tremendo escándalo de Panama Papers resumen y principales implicados. Disponible en Internet: http://theguiltycode.com/eltremendo-escandalo-de-panama-papers-resumen-y-principales-implicados/ Consultado 15.03.2018.

27. VARGAS, Carlos y CATÓLICO, Diego. (2007). La responsabilidad ética del Contador Público. En: Revista Activos, Vol. 7 № 12. Bogotá: Universidad Santo Tomas.

Para citar este artículo:
OSPINA, Tatiana. (2019). Más allá de los Paraísos Fiscales. La ética contable como factor determinante en la construcción de confianza. En: Teuken Bidikay, Vol. 10 No 14. Medellín: Politécnico Colombiano. Pp. 29-42. doi:10.33571/teuken.v10n14a1 